\title{
História dos tratamentos biológicos
}

\section{Biologicals Treatments's History}

\author{
Sérgio Paulo Rigonatti ${ }^{1}$
}

\begin{abstract}
Resumo
Contexto: Trata-se de uma discussão de como surgiram os tratamentos biológicos no decorrer da história da psiquiatria.

Palavras-chave: História da psiquiatria, tratamentos biológicos, cardiazol, ECT, insulinoterapia.
\end{abstract}

\begin{abstract}
Context: It's about a discussion on how begun the biological treatment throughout Psychiatry History.
\end{abstract}

Keywords: Psychiatry history, biological treatment, ECT, insulin therapy.
O homem, desde o tempo dos gregos, tentava curar alterações do comportamento humano através da comoção cerebral, que nada mais é do que um susto. Assim sendo, os antigos gregos jogavam tais pessoas dos penhascos do Mar Tirreno na tentativa de fazê-los recobrar a lucidez.

Ainda na Grécia, empregava-se também a cura pelo sono, o qual era denominado Sono do Templo, ou incubação, sendo que, de acordo com historiadores, o principal deles ficava em Epidauro, ainda que centenas de templos dedicados a Esculápio tenham sido construídos em diferentes partes do mundo antigo. Supunha-se que o sonho revelava ao paciente aquilo que precisaria para melhorar (F.A. pág. 55).

Asclepíades, no século I d.C., prescrevia banhos reconfortantes e música suave como medidas terapêuticas para os doentes mentais.
O emprego da eletroterapia não-convulsiva como método para melhorar sintomas, provavelmente por sugestão, data de Scribonius Largus (aproximadamente em 47 d.C.), que tratava as dores de cabeça de um imperador romano com uma enguia elétrica.

A eletroterapia não-convulsiva foi empregada de modo generalizado no final do século XIX e era defendida pelos neurologistas W. H. Erb, alemão, e G. B. Buchenne, francês.

Em 1872, é editado em Barcelona um tratado denominado Electroterapia (Método y procedimentos de Electrizacion), destinado ao tratamento das neuralgias.

Provavelmente, o primeiro tratamento eletroconvulsivo para doença mental foi aplicado pelo médico francês J. B. Leroy, em 1755, em um paciente com 
cegueira psicogênica. Quase um século depois, o alemão F. L. Augustinis relatou caso semelhante. Tais experiências foram isoladas e não tiveram prosseguimento.

Durante a segunda e terceira décadas do século $\mathrm{XX}$, começaram a surgir terapias biológicas que abriram horizontes importantes para a cura dos doentes mentais, sendo que um dos pesquisadores, o qual criou a malarioterapia e ganhou o Prêmio Nobel, foi o alemão Julius Von Wagner-Juaregg (1857-1940), que introduziu a terapia da febre e transmitiu malária a seus pacientes parésicos (portadores de paralisia geral progressiva).

O neurologista português Egas-Muniz, também ganhador do Prêmio Nobel, criou a lobotomia préfrontal e a utilizou em pacientes que não respondiam a outras medidas terapêuticas, bem como em obsessivos e melancólicos. A primeira lobotomia foi realizada em 1935.

Na década de 20 do século passado, Ladislau Von Meduna (1896-1964), julgando que a esquizofrenia e a epilepsia eram incompatíveis (baseado em estudos gliais), criou a terapêutica do "choque cardiazólico", ou seja, provocava convulsões para atingir a cura e abrir um novo campo terapêutico. Ele redescobriu os benefícios da terapia de choque, esquecida desde os tempos de Avenbrugger.

As primeiras descrições do uso de cânfora para tratar portadores de transtornos mentais parecem remitir ao século XVI, quando Paracelsus a utilizava para curar pessoas "lunáticas".

Segundo Abrams (1992), a primeira citação publicada é atribuída a Leopoldo Von Avenbrugger, que, em 1764, tratava a mania vivorum com cânfora a cada duas horas, até que surgissem as convulsões. A princípio, usou a cânfora e depois o cardiazol ou o metrazol (Pentilenetetrazol). Na época, Von Meduna era superintendente do Real Hospital Mental do Estado em Budapeste, Hungria.

Ugo Cerletti (1877-1963), juntamente com Bini, na tentativa de tornar as convulsões terapêuticas mais eficientes, pesquisou a possibilidade de serem efetuadas convulsões elétricas, cuja primeira comunicação foi apresentada no "Encontro da Associação Psiquiátrica Suíça”, realizado em Müsinger, Berna, em maio de 1937, e em 1938 foi realizada a primeira aplicação de uma corrente elétrica em um paciente esquizofrênico, com melhoras.

A eletroconvulsoterapia (ECT) foi o primeiro tratamento biológico com eficácia inquestionável em psiquiatria.

Em 1937, Flamberte introduziu a convulsoterapia por acetilcolina. Neste método, a injeção intravenosa de acetilcolina causava parada cardíaca de 30 a 50 segundos e inconsciência de curta duração.

Aplicações de cerca de $600 \mathrm{mg}$ de acetilcolina era indicadas para esquizofrenia. O psiquiatra e professor
Lopes Ibor utilizava $200 \mathrm{mg}$ em neuroses ansiosas. Observavam-se leve dificuldade respiratória, pulso lento, tosse, entre outros.

Alguns tratamentos somáticos usados no passado atualmente têm apenas interesse histórico, e entre eles podemos citar as sangrias, os eméticos e os purgativos.

Chama-nos, todavia, a atenção o "tratamento pelo sono" introduzido por Klaesi, psiquiatra suíço, em 1922.

O sono prolongado, ou um estado semelhante ao sono (durante cerca de dez dias), era induzido por meio de drogas narcóticas como hidrato de cloral, paraldeído e barbitúricos. Para o término do tratamento, reduziase gradativamente a medicação, a fim de evitar-se confusão mental ou delirium. Klaesi valorizava o aspecto psicológico do tratamento e enfatizava a necessidade de psicoterapia após ele. Em meados do século XX, ainda era usado para estados neuróticos agudos, como, por exemplo, neurose de guerra e estados passionais.

Em 1920, a terapia através do dióxido de carbono era usada para o tratamento de psicóticos, mas foi abandonada quando as terapias convulsivas foram introduzidas.

Von Meduna, em 1947, tratava de psiconeuróticos com uma mistura de $30 \%$ de $\mathrm{CO}_{2}$ e $70 \%$ de $\mathrm{O}_{2}$. Estão registrados bons resultados em pacientes com sintomas de conversão, ansiedade e instabilidade emocional.

No Brasil, Antonio Carlos Pacheco e Silva introduziu a eletroconvulsoterapia na Clínica Psiquiátrica do Hospital das Clínicas.

Em 1948, o Prof. Antonio Carlos Pacheco e Silva, catedrático de psiquiatria e responsável pela então Clínica Psiquiátrica, solicitou um espaço no Hospital das Clínicas para o atendimento de pacientes com alterações de cunho psiquiátrico, pois tal atendimento estava sendo realizado em local precário, no Departamento de Assistência aos Psicopatas, na Rua Jaceguai. Lá eram proferidas as aulas de psiquiatria aos acadêmicos de medicina, e eram atendidos os pacientes de ambulatório. Os casos que necessitassem de internação eram encaminhados ao Hospital do Juqueri. O Prof. Cantídio de Moura Campos concedeu ao Prof. Pacheco e Silva autorização para que atendesse provisoriamente os pacientes psiquiátricos em seu ambulatório no terceiro andar do Hospital das Clínicas, às quintas-feiras, no dia de reunião da Clínica, quando o mesmo ficava desocupado. E em 21 de fevereiro de 1948 foi atendido o primeiro paciente, Itália Isola, pelo Prof. Fernando de Oliveira Bastos.

Os serviços de ambulatório de ECT tiveram início em fevereiro de 1952, sob a direção do Dr. Henrique Marques de Carvalho, sendo que o primeiro paciente foi Carmelo Gross, em 05 de fevereiro de 1952 (prontuário IPq $\mathrm{n}^{\circ} 320$ ), sendo atendido pelo próprio Dr. Henrique. 


\section{Referências bibliográficas}

Abrams, R. - Electroconvulsive Therapy. 2.ed. New York, Oxford University Press, 1992.

Abrams, R. - The treatment that will not die. Psychiatric Clinics of North America 17:525-30, 1994.

AcCORNERO, F. - An eyewitness account of the discovery of electroshock. Convulsive Therapy 4:40-9, 1988.

Alexander, F.G.; Selesnick, S.T. - História da Psiquiatria. Ibrasa, 1968.

Almeida, 0.P.; Lafer, B.; Gentil, V.; Gronich, G. - 50 anos de ECT: do choque a seco ao tratamento otimizado. J Bras Psiq 5:233-40, 1988.

Bastos, F.0. - Contribuição clínica para o estudo da convulsoterapia aplicada aos distúrbios mentais nãoesquizofrênicos, 1941.

EndLER, N.S.; Persad, E. - Electroconvulsive therapy: the myths and the realities. Toronto, Hans Huber, 1988.

Fernandes, F.A. - Fundamentos de la psiquiatria actual. Editorial Paz Montalro, Madrid, 1968.

FreEdMAN, A.M.; KAPLAN, H. - Comprehensive text book of psychiatry. The Willians and Wilkins Company, Baltimore, 1967.

Fink, M. - Meduna and origins of convulsive therapy. Am J Psychiatry 14:1034-41, 1984.
Guz, I. - Terapêuticas biológicas e os distúrbios mentais. Artes Médicas, Porto Alegre, 1974.

JenKUSKY, S.M. - Public perception of electroconvulsive therapy: a historical review. Jefferson Journal of Psychiatry 10:2-11, 1992.

MedunA, L.J. - Über experimentelle Campherepilepsie. Arch Psychiatry Nervenkr 102:333-9, 1934.

MedunA, L.J. - Autobiography. Part 1. Convulsive Therapy 1:43-57, 1985

Mowbray, R.M. - Historical aspects of electric convulsant therapy. Scott Med J 4:373-8, 1959.

RuBı, E.B. - Electroterapia - Métodos e procedimentos de Electrização. Barcelona, 1872.

Sargant, W.; Slater, E.; Kelly, D. - Introdução aos métodos de tratamento físico em psiquiatria. $5^{\mathrm{a}}$ ed. Guanabara Koogan, Rio de Janeiro, 1978.

Stone, M.H. - A cura da mente. ArtMed, Porto Alegre, 1999.

The American Journal of Psychiatry, vol.94; May 1938, Supplement Proceedings of the $89^{\text {th }}$ Meeting of the Swiss Psychiatry Association At Münsingen Berne, May 29-31,1937. 